\title{
CVS Health faces a new wave of disruption
}

\author{
John M. York \\ Rady School of Management and Jacobs School of Engineering, \\ University of California San Diego, La Jolla, California, USA and \\ Ernest Mario School of Pharmacy, Rutgers University, Piscataway, \\ New Jersey, USA, and \\ Kaley Lugo, Lukasz Jarosz and Michael Toscani
nest Mario School of Pharmacy, Rutgers University, Piscataway, \\ Kaley Lugo, Lukasz Jarosz and Michael Toscani
Ernest Mario School of Pharmacy, Rutgers University, Piscataway, \\ New Jersey, USA
}

\begin{abstract}
Purpose - The purpose of this teaching case study is to change to examine how Amazon's threat may impact the pharmacy industry as a whole and whether traditional drugstore chains such as Consumer Value Stores (CVS) Health will need to re-think their business strategy, especially in the digital space, to account for potential disruption.

Design/methodology/approach - This paper presents a hypothetical case study used as a teaching exercise to guide the learner through a decision-making process. The case starts by presenting a disruption in the retail pharmacy business that the main character must navigate by using real-world data and insights, provided in the case, to formulate a recommendation.

Findings - In an extremely competitive and consolidated pharmacy market, Amazon has the potential to change the business entirely. CVS Health will potentially face strong headwinds from Amazon's PillPack and a downward trend in prescription sales. Regardless of the new competition, CVS Health continues to be innovative in the space. CVS has encompassed the mentality of becoming a one-stop-shop by expanding into areas such as specialty pharmacy, health clinics, pharmacy benefits management and innovative digital capabilities.

Originality/value - This paper provides the reader with existing and known information about the evolving retail pharmacy business and allows the reader to interpret the new information to make their own decision on how a digital business strategy team can account for potential disruption.
\end{abstract}

Keywords Amazon, Pharmacy, Digital health, Business case study, CVS Health, Pillpack

Paper type Case study

\section{Introduction}

Health care has experienced an extremely dynamic period over the past decade. In particular, the retail pharmacy business has progressed through a tremendous amount of disruptive change (Gratto and McConnell, 2016). Consumer Value Stores (CVS) Health remains the leader in the space with the largest footprint of pharmacy operating units, as

(C) John M. York, Kaley Lugo, Lukasz Jarosz and Michael Toscani. Published by Emerald Publishing Limited. This article is published under the Creative Commons Attribution (CC BY 4.0) licence. Anyone may reproduce, distribute, translate and create derivative works of this article (for both commercial and non-commercial purposes), subject to full attribution to the original publication and authors. The full terms of this licence may be seen at http://creativecommons.org/licences/by/4.0/ legalcode 
IJPHM

15,3

well as the ability to control pricing because of its pharmacy benefits management (PBM) business model and purchasing power (Fitzgerald, 2017; Anderson, 2019). Recently, however, digital business strategies have become an essential aspect of health care and a necessary driver for the optimization of the health-care experience. Consumers are shifting their preferences toward digital options, and therefore, the pressure lies on businesses to keep up. Digital is a crucial aspect of marketing and successfully engaging customers (Gratto and McConnell, 2016).

You are a newly promoted director of digital marketing at CVS Health. In reaction response to what is happening with Amazon, you and your team will need to make a presentation to CEO - Karen S. Lynch, CVS Health's chief executive, as the board is raising concerns. "How should CVS Health address this disruption?" The director must make a recommendation and build a business case argument (Appendix 1) whether CVS Health should:

- ignore the threat;

- combat Amazon's PillPack in the mail-order space (and how);

- modify its current digital business model and offerings;

- ignore any changes in digital, but determine ways to communicate its offerings; or

- focus on other sectors of its business, such as leveraging digital capabilities.

The purpose of this case is to establish a scenario that facilitates a discussion about strategic choices executives in incumbent enterprises need to make when a dynamic shock leads to a change in the competitive space. The case begins with an overview of the pharmacy business focusing specifically on retail pharmacy, mail-order pharmacy and retail health clinics. It then transitions into a discussion on the business model and key pillars of CVS Health, the leader in the pharmacy space. It ends with an overview of Amazon's business model, its entrance into the arena via the acquisition of PillPack, and potential implications for the future.

\section{The pharmacy business}

The US pharmacy industry includes five main sectors, namely, chain drug stores, independent pharmacies, supermarkets with pharmacies, mass merchants with pharmacies and mail-order/specialty pharmacies. Across these sectors, pharmacies dispense an estimated 4.5 bn prescriptions combined (Drug prescription volume US, 2019), making the prescription pharmacy business a $\$ 400$ bn market. Most of the dispensing volume comes from the generic drug market, which makes up $89 \%$ of all prescriptions while accounting for only $26 \%$ of the revenue (Fein, 2019).

Over the past five years, the total number of dispensed prescriptions has remained relatively flat, and growth rates for prescription revenues peaked in the year 2014 at $16.6 \%$ (Fein, 2019). Since then, rates have fallen to a low of $0.3 \%$ in 2017 and have struggled to rebound (Fein, 2019). This situation is, in part, due to higher generic dispensing and deflation of generic drug prices, declining inflation in brand-name drug prices and a decrease in drug spending on therapeutic areas such as pain management and infectious disease (Fein, 2019). With declining growth rates and falling margins, the battle for market share and prescription volume is critical.

\subsection{Retail pharmacy}

To understand the pharmacy business, one needs to segment each sector separately, starting with the pharmacy retailers. Chain drug stores predominantly run this sector, 
accounting for $32.2 \%$ of all prescription dispensing revenues (Table 1 and Figure 1) (Fein, 2019) and dispensing about 50\% of the total 30-day equivalent medications dispensed in the US in 2018.

Independent pharmacies, alternately, accounted for $14 \%$ of revenues, while mass merchants/supermarkets with pharmacies and long-term care pharmacies split the remaining $19 \%$. Revenues aside, chain drug stores are the busiest format in the pharmacy market when looking at the index of prescriptions dispensed per pharmacy location; however, growth in the number of new chain drug store locations has been flat over the past few years (Fein, 2019).

\begin{tabular}{lrrrr}
\hline & \multicolumn{2}{c}{ Prescriptions (billions) } & \multicolumn{2}{c}{ Share of revenues } \\
Dispensing format & 2017 & $2018 \mathrm{E}$ & $2017(\%)$ & 2018E (\%) \\
\hline Chain drugstores & $\$ 133.8$ & $\$ 136.5$ & 32.5 & 32.2 \\
Independent pharmacies & $\$ 58.1$ & $\$ 58.4$ & 14.1 & 13.8 \\
Mass merchant pharmacies & $\$ 34.8$ & $\$ 35.5$ & 8.4 & 8.4 \\
Supermarket pharmacies & $\$ 31.9$ & $\$ 30.6$ & 7.7 & 7.2 \\
Mail pharmacies & $\$ 135.0$ & $\$ 144.2$ & 32.8 & 34.0 \\
Long-term care pharmacies & $\$ 18.0$ & $\$ 18.6$ & 4.4 & 4.4 \\
Total & $\$ 411.6$ & $\$ 423.7$ & 100 & 100
\end{tabular}

Notes: Reprinted [adapted] from "The 2019 Economic Report on US Pharmacies and Pharmacy Benefit Managers," by A. J. Fein (2019), Drug Channels Institute. Copyright 2019 by Pembroke Consulting, Inc., d/b/a Drug Channels Institute

Table 1. Prescription dispensing revenues by dispensing format, 2017 vs 2018
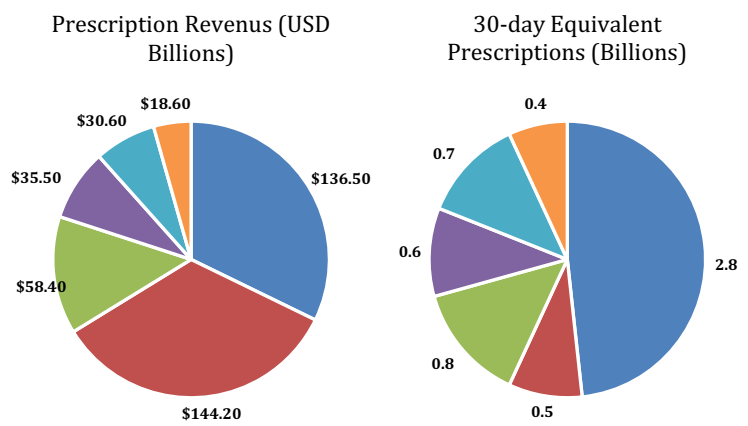

Locations (Thousands)

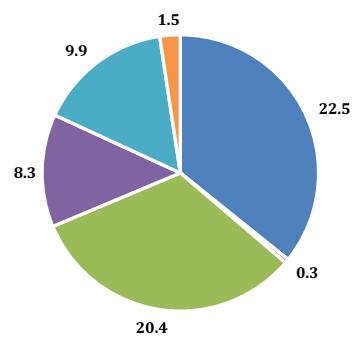

- Chain Drugstores

- Mail Pharmacies

Independent Pharmacies

" Mass Merchant Pharmacies

w Supermarket Pharmacies

- Long-term Care Pharmacies

Note: Reprinted [adapted] from "The 2019 Economic Report on US Pharmacies and Pharmacy Benefit Managers," by A. J. Fein (2019), Drug Channels Institute. Copyright 2019 by Pembroke Consulting, Inc., d/b/a Drug Channels Institute
Figure 1.

Total US pharmacy industry prescription revenues, prescriptions and locations by dispensing format, 2018 
IJPHM

15,3

\section{6}

Table 2.

Number of 30-day equivalent prescriptions, by dispensing format, 2017 vs 2018
In considering these segments, one needs to recognize that retail chains continue to dominate prescription activity (Table 2); however, over the past five years, they have faced pressure generating profits caused by flat revenue growth, regulatory challenges and external competition (Fein, 2019). Figure 2 highlights the year-over-year growth, from 2015 to 2018, of same-store prescription counts by chain pharmacies (Fein, 2019). In general, growth has remained flat with minor fluctuations between $-3 \%$ and $10 \%$ across the three major retailers, CVS Health, Walgreens Boots Alliance and Rite Aid. As retail pharmacy chains struggle to return a profit by prescription volume alone, vertical and horizontal mergers and acquisitions have significantly reshaped the pharmacy and PBM relationship over the past decade. Traditional drugstores have become integrated pharmacy health-care companies that offer preventive care services such as immunizations, health screenings and monitoring for chronic health conditions. Among the 15 largest pharmacies ranked by total prescription dispensing revenues (Table 3), four are central-fill mail and specialty pharmacies operated by PBM groups, including Express Scripts, Caremark, UnitedHealth Group's OptumRx and Humana (Fein, 2019).

\begin{tabular}{|c|c|c|c|c|}
\hline \multirow[b]{2}{*}{ Dispensing format } & \multicolumn{2}{|c|}{ Prescriptions (mlns) } & \multicolumn{2}{|c|}{ Share of prescriptions } \\
\hline & 2017 & $2018 \mathrm{E}$ & $2017(\%)$ & $2018 \mathrm{E}(\%)$ \\
\hline Chain drugstores & 2,794 & 2,822 & 47.6 & 47.5 \\
\hline Independent pharmacies & 848 & 849 & 14.5 & 14.3 \\
\hline Mass merchant pharmacies & 625 & 631 & 10.7 & 10.6 \\
\hline Supermarket pharmacies & 726 & 738 & 12.4 & 12.4 \\
\hline Mail pharmacies & 474 & 504 & 8.1 & 8.5 \\
\hline Long-term care pharmacies & 399 & 402 & 6.8 & 6.8 \\
\hline Total & 5,866 & 5,945 & 100 & 100 \\
\hline
\end{tabular}

Notes: Reprinted [adapted] from "The 2019 Economic Report on US Pharmacies and Pharmacy Benefit Managers," by A. J. Fein (2019), Drug Channels Institute. Copyright 2019 by Pembroke Consulting, Inc., d/b/ a Drug Channels Institute

\section{Figure 2.}

Year-over-year change in same-store prescription count, by chain, 2013 to 2018

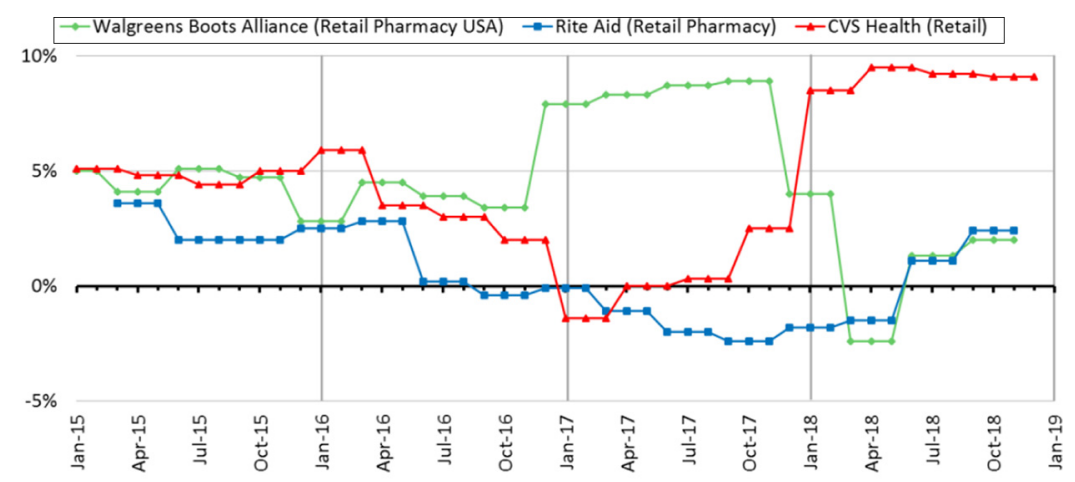

Note: Reprinted [adapted] from "The 2019 Economic Report on US Pharmacies and Pharmacy Benefit Managers," by A. J. Fein (2019), Drug Channels Institute. Copyright 2019 by Pembroke Consulting, Inc., d/b/a Drug Channels Institute 


\begin{tabular}{|c|c|c|c|c|c|}
\hline Pharmacy & Parent organization & $\begin{array}{l}\text { Estimated } \\
\text { prescription revenue } \\
\text { from specialty drugs } \\
\text { (2018, USD billions) }\end{array}$ & $\begin{array}{l}\text { Change in } \\
\text { revenue } 2018 \\
\text { vs } 2017(\%)\end{array}$ & $\begin{array}{l}\text { Share of } \\
\text { prescription } \\
\text { revenues from } \\
\text { specialty drugs }(\%)\end{array}$ & \\
\hline CVS Specialty/Aetna & CVS Health & $\$ 37.0$ & +6 & 25 & \\
\hline $\begin{array}{l}\text { Specialty } \\
\text { Accredit/Freedom }\end{array}$ & Cigna/Express & $\$ 30.7$ & +7 & 21 & 337 \\
\hline $\begin{array}{l}\text { Fertility/Cigna } \\
\text { Specialty }\end{array}$ & Scripts & & & & \\
\hline $\begin{array}{l}\text { Alliance Rx } \\
\text { Walgreens Prime/ } \\
\text { Walgreens Stores }\end{array}$ & $\begin{array}{l}\text { Walgreens Boots } \\
\text { Alliance }\end{array}$ & $\$ 19.6$ & +23 & 13 & \\
\hline BriovaRx & United Health Group & $\$ 16.8$ & +29 & 11 & \\
\hline Diplomat Pharmacy & Diplomat Pharmacy & $\$ 4.8$ & +6 & 3 & \\
\hline Humana Specialty & Humana & $\$ 3.2$ & +3 & 2 & \\
\hline $\begin{array}{l}\text { Kroger Specialty/ } \\
\text { Kroger Stores }\end{array}$ & Kroger & $\$ 2.8$ & +24 & 2 & \\
\hline $\begin{array}{l}\text { Specialty Pharmacy } \\
\text { Solutions }\end{array}$ & Mckesson & $\$ 1.6$ & +7 & 1 & \\
\hline US Bioservices & AmerisourceBergen & $\$ 1.4$ & +23 & 1 & \\
\hline Walmart Specialty & Walmart & $\$ 1.0$ & +4 & 1 & Table 3. \\
\hline All other & $\mathrm{n} / \mathrm{a}$ & $\$ 27.4$ & $\mathrm{n} / \mathrm{a}$ & 20 & Prescription \\
\hline Total & & $\$ 146.2$ & +6 & 100 & revenues and market \\
\hline \multicolumn{5}{|c|}{$\begin{array}{l}\text { Notes: Reprinted [adapted] from "The } 2019 \text { Economic Report on US Pharmacies and Pharmacy Benefit } \\
\text { Managers," by A. J. Fein (2019), Drug Channels Institute. Copyright } 2019 \text { by Pembroke Consulting, Inc., d/b/ } \\
\text { a Drug Channels Institute }\end{array}$} & $\begin{array}{r}\text { share from specialty } \\
\text { pharmaceuticals, by } \\
\text { company, } 2018\end{array}$ \\
\hline
\end{tabular}

\subsection{Mail-order pharmacy}

Another critical sector is the mail-order business. With many retailers integrating mail-order pharmacies into their business model, it is important to dive deeper into this sector. Despite not being one of the busier sectors and representing only $1 \%$ of the dispensing locations, mail pharmacies generate about $34.5 \%$ of the industry's total prescription revenues or around $\$ 144$ bn (Table 1 and Figure 1) (Fein, 2019). The impact of specialty drugs, which make up $70 \%$ of revenues from mail-order pharmacies, has been significant. The total dispensing revenues from specialty drugs at mail, chain, independent, long-term care and supermarket pharmacies reached $\$ 146.1 \mathrm{bn}$ in 2018 , with $\$ 104.7 \mathrm{bn}$ coming from mail pharmacies (Figure 3) (Fein, 2019). Other drivers of growth in profits in mail-order include increased efficiency, decreased waste and improvements in delivery networks (Mail-Order Pharmacy Startups and Opening a Mail Order Pharmacy Business, 2020).

Generally, patients with chronic medical illnesses that require long term medications use mail-order pharmacy. They focus on patients' convenience, satisfaction and loyalty. Patients can request all their prescriptions online and have them delivered at any time without leaving home or waiting in long lines (Daily, 2019).

In contrast, other mail-order pharmacies specialize in niche disease areas where mitigation of challenging diseases and complex treatment regimens are fundamental. These specialty pharmacies focus on high cost, high touch, self-administered specialty pharmaceuticals for people with severe health conditions requiring complex therapies in disease states ranging from cancer, multiple sclerosis and rheumatoid arthritis to rare genetic conditions. They often provide additional services such as patient therapy 


\section{IJPHM \\ 15,3}

\section{8}

Figure 3.

Specialty drug prescription revenues by dispensing format, 2018

\section{Specialty Prescription Revenues (USD Billions)}

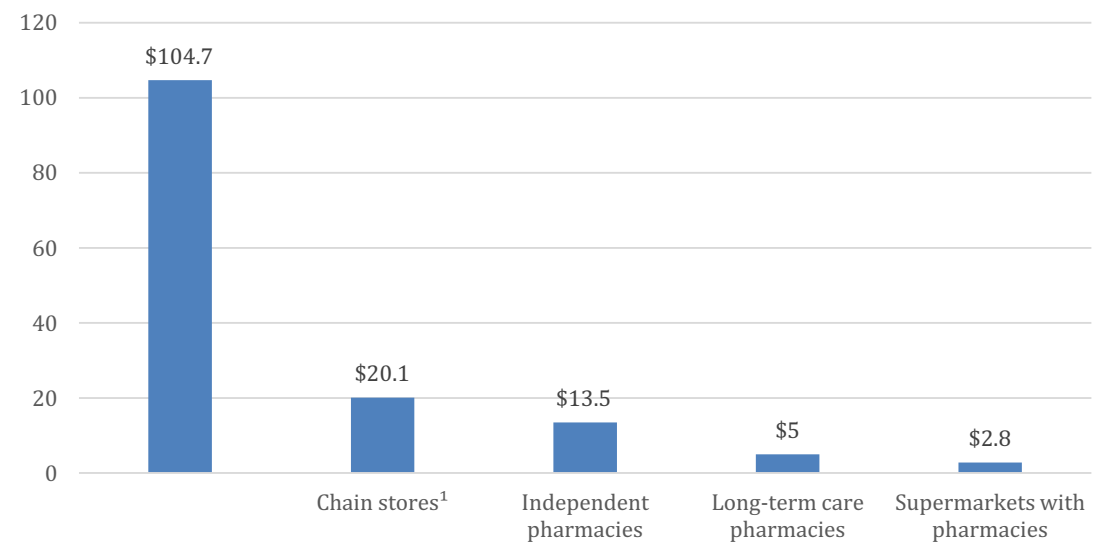

Note: Reprinted [adapted] from "The 2019 Economic Report on US Pharmacies and Pharmacy Benefit Managers," by A. J. Fein (2019), Drug Channels Institute.

Copyright 2019 by Pembroke Consulting, Inc., d/b/a Drug Channels Institute

management, disease state education and support services to enhance medication compliance (Specialty Pharmacy, 2017).

Despite the many advances in mail-order, it may not be the right option for many patients. This consideration is especially true for those patients who prefer the personal touch of a face-to-face consultation with the pharmacist. Retail pharmacies recognize this practice is one of their strongest assets, and continue to react and adapt their models to highlight the benefits of taking a trip to the pharmacy.

\subsection{Retail health clinics}

To supplement the prescription business and respond to increased demands for access by patients due to the Affordable Care Act, chain pharmacies such as CVS with its Minute $\mathrm{Clinic}^{\circledR}$, are incorporating built-in retail health clinics. This movement offers a unique development of the current retailer landscape. Over the past 15 years, the retail health clinic sector grew from a few retail clinic operations to about 2,000 retail health clinic locations across the USA (Godman, 2016). Retail health clinics offer consumers the convenience of a one-stop-shop for treatment and prescriptions, lower cost for services and locally present treatment centers.

Traditionally, retail clinics provided a limited scope of services. These include seasonal health issues, minor illnesses and pregnancy testing. However, in the past year, companies such as CVS and Walgreens have begun to expand their focus into chronic disease management, novel technologies to incorporate video visits, health screenings and physicals (MinuteClinic ${ }^{\circledR}$ History, 2019). CVS owns and operates the majority $(52 \%)$ of retail clinics, however, despite the vast amount of clinics that are still open to date, the clinical revenues generated through the operation of these clinics are only a small fraction of the retailer's prescription revenues (Fein, 2019). 


\section{Consumer value stores (CVS) Health}

CVS Health's business model (Appendix 2 for an overview of business models) splits into two main operations, namely, the retail brick-and-mortar space and the managed services for the health-care space. CVS uses several strategies to drive growth in these models, including market penetration, supply chain management services, cost leadership generic strategies and, most recently, its digital strategy. In this section, the reader will learn more about the respective strategies and how CVS incorporates them into the pharmacy business.

\subsection{History}

CVS began in 1963 as a chain of health and beauty aid stores. The firm added pharmacies four years later in 1967 (Tabuchi, 2015). As retail health clinics took off in the twenty-first century, CVS partnered with MinuteClinic ${ }^{\circledR}$ to open its first CVS Pharmacy walk-in medical clinics in 2006 (MinuteClinic History, 2019). In 2007, the firm took on a new name, CVS Caremark Corporation, after merging with the PBM company Caremark Rx ${ }^{\circledR}$. In 2014, the company renamed itself as CVS Health, following its decision to reflect broader health care commitment and remove tobacco products from store shelves (CVS Caremark announces a corporate name change to CVS Health to reflect broader health care commitment, 2014). In December 2017, CVS agreed to acquire Aetna, one of the largest insurance providers, for \$69bn (CVS Health to Acquire Aetna; Combination to provide consumers with a better experience, reduced costs and improved access to health care experts in homes and communities across the country, 2017).

CVS Health's assets include CVS Pharmacy ${ }^{\circledR}$, CVS Caremark ${ }^{\circledR}$, CVS Specialty ${ }^{\circledR}$ and MinuteClinic ${ }^{\circledR}$. This type of pipeline business model is part of the CVS strategy to transform inputs into outputs in a sequential manner with customers benefitting along the patient journey as they seek medicines, consumer goods and health-care services (Anderson, 2019).

\subsection{Retail pharmacy}

CVS Pharmacy is currently the most prominent drug store chain in the USA based on market share, generating about $24 \%$ of total prescription drug pharmacy revenues (Fein, 2019). One of its key growth strategies is market penetration, which aims to maximize the companies reach and customer access (Anderson, 2019). A clear reflection of this strategy is the 10,000 stores CVS built located across 49 states, the District of Columbia, Puerto Rico and Brazil (CVS Health at a Glance, 2019). In total, $82 \%$ of the population lives within 10 miles from a store and $71 \%$ live within 5 miles (Yanofsky and Zhou, 2017).

As part of its business strategy to retain current customers, CVS developed an ExtraCare ${ }^{\circledR}$ loyalty program. The program has over 70 million members who use the program regularly, making it the most extensive retail loyalty program in the country (Customers Are Seeing Double at CVS/pharmacy This Fall, With More Rewards for ExtraCare ${ }^{\circledR}$ Members, 2012). The loyalty program leverages customer data to personalize and create consumer-specific offers based on historical spending patterns, interests and recent searches. The firm prints customized offers on shopping receipts send them electronically and populate the CVS mobile app with these engagements (Customers Are Seeing Double at CVS/pharmacy This Fall, With More Rewards for ExtraCare Members, 2012).

CVS also offers a variety of personalized and convenient options for prescription pick up, including a drive-thru window, home delivery and 1-h curbside pick-up. Alongside its prescription delivery, customers can opt-in for the delivery of thousands of over the counter health products. Other significant customer service enhancements include those made to digital capabilities. 
IJPHM

15,3

340

\subsection{Digital prescription management and capabilities in retail pharmacy}

As the company combined its traditional pharmacy stores and digital capabilities, its business model shifted to a more click-and-mortar approach. CVS Health's digital website and mobile application give patients and family members full control of their prescriptions at their fingertips. Digital capabilities involve multiple services. These include viewing and managing prescriptions, requesting prescription transfers, financial summary tracker, prescription scheduler, drug information center, pill identifier and alert management tools (Pharmacy: Manage, transfer and refill prescriptions online: CVS Pharmacy, 2019).

In 2016, CVS introduced an end-to-end mobile app and payment solution, CVS Pay ${ }^{\circledR}$, to help streamline the in-store experience. The capability speeds up the traditional pick-up process by allowing customers to verify their identity, pick up prescriptions, pay and earn ExtraCare loyalty points through the mobile app (CVS Pharmacy Launches Breakthrough, end-to-end mobile payment experience, 2016). The next section discusses several important digital capabilities incorporated into the CVS business model.

\subsection{MinuteClinic ${ }^{\circledR}$}

To further add to its pipeline of health-care assets and services, CVS Health expanded its business model to incorporate retail health clinics, CVS MinuteClinic ${ }^{\circledR}$. These medical clinics operate inside about $13 \%$ of the US CVS Pharmacies, making them the largest retail clinic business in the US with over 1,000 locations and $52 \%$ of the market share of retail clinics (Yanofsky and Zhou, 2017; Fein, 2019). In 2018, this unit's estimated revenue accounted for less than $1 \%$ of CVS Health's total dispensing revenue; however, these clinics will play an instrumental role as CVS begins to implement its plans of converting CVS retail locations into health-care hubs (Fein, 2019). MinuteClinic ${ }^{\circledR}$ staffing includes a nurse practitioner and a physician's assistant. These practitioners provide multiple services, including health screenings, wellness services, physicals, vaccinations, skin screenings and diagnosis and treatment of minor health conditions that are cost-effective to patients (MinuteClinic ${ }^{\circledR}$ Services, 2018).

To further expand MinuteClinic ${ }^{\circledR}$ access and incorporate digital technologies, CVS Health partnered with three prominent telemedicine companies giving patients access to telehealth services in various regions of the country. The online telehealth visit offers comparable services to the in-person clinic all through a virtual video communication platform available $24 \mathrm{~h}$ a day, seven days a week (MinuteClinic ${ }^{\mathbb{B}}$ Video Visit, 2018).

\subsection{CVS Specialty}

Transitioning from CVS's retail pharmacies and medical clinics, this discussion segues into the specialty mail-order pillar of its business. CVS Specialty/Aetna Specialty Pharmacy, which falls under CVS Health, is the specialty pharmacy division that provides mail order pharmacy services for individuals with chronic or genetic diseases who require complicated and expensive drug therapies. CVS Health operates 25 retail specialty pharmacy stores and 11 specialty mail-order pharmacies, making them the largest specialty pharmacy in the USA.

In 2018, CVS Health's specialty division brought in an estimated $\$ 37 \mathrm{bn}$ in prescription revenues, which was a $25 \%$ share of prescription revenues (Fein, 2019). This growth was a $6 \%$ increase in specialty pharmaceutical revenues from 2017 (Table 3). CVS Health continues to expand its specialty business and, in 2018, made five new publicly announced specialty pharmacy acquisitions (Fein, 2019). 


\subsection{Prescription and vendor benefits management}

The final pillar of CVS Health's business is CVS Caremark ${ }^{\circledR}$, the PBM subsidiary. In 2017, CVS Health brought in $\$ 210 \mathrm{bn}$ in revenue, from which its PBM services contributed $62 \%$ and the retail pharmacy contributed $38 \%$. The PBM pillar is part of the supply chain management, service strategy. This approach enables CVS to achieve a low-cost competitive advantage and operational effectiveness that benefits customers. The PBM administers prescription drug plans from various plans. These include commercial health plans, selfinsured employer plans, union plans, Medicare Part D plans, the Federal Employees Health Benefits Program, state government employee plans, managed Medicaid plans, etc. Its vast PBM network covers over 75 million plan members and includes more than 68,000 retail pharmacies (both CVS and non-CVS pharmacies) (Fein, 2019). To drive its competitive lowcost advantage, the PBM aggregates the bargaining power of its entire network against pharmaceutical suppliers. In return, CVS generates profits by retaining a portion of the cost savings (Anderson, 2019).

In mid-2019, CVS Health introduced a new vendor benefit management (VBM) service to help PBM clients onboard and manage third-party health vendors that provide digital and non-digital health and wellness solutions. The goal of the open platform is to simplify the integration of third-party vendors into existing relationships with CVS Health, streamline contracting and billing, standardize member eligibility and collect and report usage and outcomes data. VBMs will make it possible to develop and implement disruptive novel tools and care models that supplement patient care and help manage insomnia, pain, smoking cessation, substance abuse support, medication adherence, fitness goals and more. In 2018, the typical employer offered 14 supplementary health-care solutions, with some larger employers offering even more ("VBM," no date). VBMs allows for the integration of many unique digital health apps and capabilities, which leads us into the next section.

\subsection{Further expansion into digital health}

With Aetna by their side, management expects CVS Health to spend about $\$ 350 \mathrm{~m}$ on technology in 2019 to improve patient care and help transform its network of over 9,000 stores (Garrity, 2019). Aetna has several digital mediums that help patients take control of their health-care journey, including the iTriage ${ }^{\circledR}$ application, the Aetna Mobile app and the Attain ${ }^{\circledR}$ program. Aetna's iTriage ${ }^{\circledR}$ app assists patients with symptom navigation, health education, prescription management, video-based physician visits and drug pricing transparency (Comstock, 2015). The Aetna Health ${ }^{\mathrm{SM}}$ Mobile application allows members to manage and access benefits information, locate physicians and facilities, moderate work-life balance and track mood (Aetna Mobile, 2018). Finally, the Attain ${ }^{\mathrm{SM}}$ program also known as the Aetna Health ${ }^{\circledR}$ Mobile App), which recently partnered with Apple, is a personalized wellbeing app that provides members with personalized goals, daily activity trackers, tips for healthy lifestyle choices and reminders to get their annual check-ups and seasonal vaccinations (Attain ${ }^{\text {SM }}$ Mobile, 2018). These tools, in combination with CVS Health's assets, can help unlock necessary data to deliver increased consumer engagement, enhance business benefits and drive innovative business ventures.

CVS Health's 2019 Investor Day presentation discusses the integration of machine learning and artificial intelligence as essential tools to drive consumer behavior change and improve health outcomes. Using all the data collected from its key business pillars, CVS Health is working to develop an intelligent engagement platform that will incorporate a consumer-focused approach to communication. The platform will integrate the consumer journey, create touchpoints and situational context and personalize content management. If successful, CVS Health will remain at the forefront of digital health's evolution. However, 
IJPHM 15,3

\section{2}

if not careful, CVS may allow Amazon to catch up, whose reputation and reach quickly has allowed them to disrupt many sectors.

\section{Amazon acquires PillPack}

While CVS focused on its core businesses and competitive challenges with rival chain pharmacies and insurers, it failed to notice the emergence of a disruptive influence involving a startup called PillPack and Amazon's acquisition of this firm. Amazon, the world's largest e-retailer, offers a product portfolio ranging from home goods, services and health care. Its robust online business model allows it to rapidly expand into various industries, increase business efficiencies, decrease prices and provide excellent service for its customers.

\subsection{Pillpack}

PillPack, currently licensed nationwide in 49 states (excluding Hawaii), encompasses over 150 pharmacy distribution center licenses in 5 states. Since the beginning of 2019, PillPack had established pharmacy licenses allowing it to ship and operate its mail-order business in multiple states throughout the USA. The Utilization Review Accreditation Commission, a specialty pharmacy accreditation organization, also permitted PillPack to open a specialty pharmacy in the New Hampshire location (Fein, 2019).

Pill Pack's niche in the pharmacy service is its application of the multi-dose drug dispensing (MDD) system to patient homes. Inpatient facilities and long-term care pharmacies have used such a system for many years, while pharmacy retailers historically packaged each medication separately into clear amber vials. In 2006, a study by researchers from Walter Reed Army Medical Center found that placing medicine in blister packs increased compliance from $61 \%$ to $97 \%$ (Hedgecock, 2015). With these results in mind, PillPack developed its customized MDD box that contained a two-week supply of daily blister packs labeled with special instructions regarding the administration of each medicine. The service provided with no additional costs beyond the prescription price itself also gives customers access to a pharmacy staff they can contact online or by phone 24/7.

Another attractive aspect of Pill Pack's business is the digital mobile application and website, which focus on a better, more straightforward patient experience. PillPack believes that the best solution to adherence is simplicity. Users can import their medication lists using their name, date and social security number, according to Comstock (2015). Once the app has imported the medication list, it will auto-populate dose times and regimen. The app can also create time-based and location-based reminders, which use the phone's global positioning system (GPS) and can trigger an alert when the patient is in the desired location. The app records data about medication adherence and missed doses that users or caregivers can analyze and improve. The application is also available for the Apple Watch ${ }^{\circledR}\left(\right.$ Comstock, $^{\circ}$ 2015). An online pharmacy player with a strong focus on customer service, convenience and digital makes PillPack the perfect fit for a company such as Amazon, who is eager to disrupt health care.

\subsection{The deal}

Over the past several years, Amazon hinted at its entry into the health-care arena. The first subtle signal occurred in 2017 when Amazon acquired Whole Foods, obtaining over 470 storefronts worldwide with the majority in the US, giving it a physical footprint in 45 states (Nusca and Rapp, 2017). In the same year, Amazon received approval for wholesale pharmacy licenses in at least 12 states. Despite speculations that Whole Foods would be the jumping point, Amazon had a different plan. On June 28, 2018, Amazon announced that it would acquire PillPack, a high-growth mail-order pharmacy business with an 800-plus 
person workforce, for $\$ 753 \mathrm{~m}$. Before the acquisition, the PillPack was on track to generate $\$ 299 \mathrm{~m}$ in annual revenue (Farr, 2019). Management forecasted growth in 2019 to be $\$ 635 \mathrm{~m}$ (Farr, 2019).

\subsection{The Amazon effect}

Amazon's hyper-focused approach to superior customer service and efficiency has created tremendous growth for the company across a variety of sectors. Independently, Amazon's network makes it one of the largest retailers worldwide, with over $310 \mathrm{mln}$ active customers, $100 \mathrm{mln}$ Prime Members and approximately $5 \mathrm{mln}$ sellers. About $64 \%$ of households have subscribed to Amazon Prime and more than $45 \%$ of US households live within a few miles of an Amazon fulfillment center. By promoting the pharmacy service to a select group of Prime subscribers, Amazon can potentially provide even more growth to the PillPack network (Leadem, 2018). Amazon's business model focuses on three key areas making it one of the most desirable online retailers, namely, competitive pricing, efficiency and convenience.

Amazon has invested time and money toward creating the best delivery network and technology. Its current delivery capabilities allow customers to receive orders as soon as the same day in some states, within one business day for Prime members and within several business days for standard orders. The current pharmacy supply chain is highly intricate, with many intermediaries playing a role in the complex business model and skimming a piece of the profit. While PBMs strive to negotiate rebates from drug manufacturers, price inflation occurs at each stage of the supply chain process. By cutting out the middleman, Amazon can use its business framework and supply chain technology to streamline processes and drive lower drug costs. Another way Amazon can drive lower drug prices is through its vast purchasing power and ability to negotiate with health insurers and drug makers.

2018 Pharmacy Satisfaction Pulse Survey queried consumers with the following question: "if Amazon was to provide prescription drug filing services, how interested would you be in filing your prescription with them?" (Fein, 2019). Approximately 16\% of consumers from various dispensing formats (e.g. chain drug stores, independent pharmacies, supermarket pharmacies, mass merchant pharmacies and mail pharmacies) indicated they would be very interested (Figure 4) (Fein, 2019). Over 50\% of consumers combined reported they would be very interested or somewhat interested (Figure 4) (Fein, 2019).

Amazon's purchase of the online pharmacy PillPack created much uncertainty about its intentions and future health-care strategy. Although there is limited information around Amazon's next steps as it enters the pharmacy business, one thing this technology giant can guarantee. It will create significant disruption. The acquisition of an online pharmacy is likely just the beginning. It will be interesting to see if or how Amazon approaches the retail pharmacy, retail clinic, $\mathrm{PBM} / \mathrm{VBM}$, specialty and insurance aspects of this complex business.

\section{Addressing management's request: analysis, recommendations and a business case}

In an extremely competitive and consolidated pharmacy market, Amazon offers the potential to disrupt the pharmacy business entirely and even health-care delivery. CVS Health will potentially face strong challenges from Amazon's PillPack, in addition to the downward trend in prescription sales due to the evolving prescription marketplace driven by insurers. Regardless of this new competitor, CVS Health continues to be innovative in the space. Instead of being a singular-focused business, CVS has encompassed the mentality of becoming a one-stop-shop by expanding into areas such as specialty pharmacy, health 


\section{IJPHM \\ 15,3}

\section{4}

Figure 4.

Consumer interest in obtaining prescriptions from Amazon, by usual dispensing format, 2018

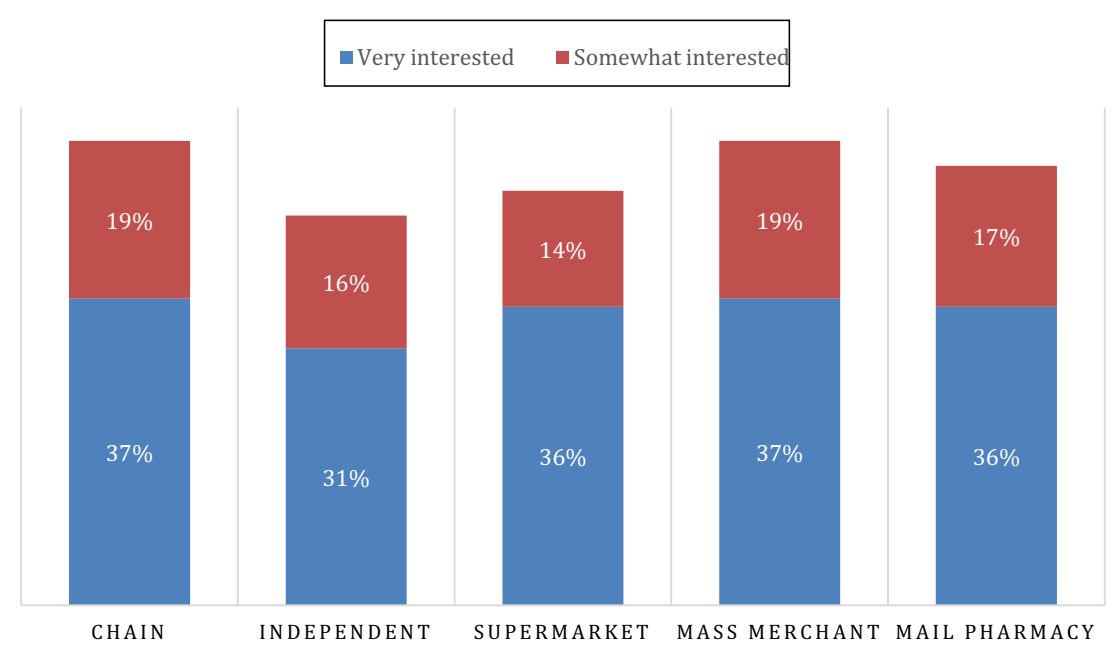

Source: Drug Channels Institute analysis of Boehringer Ingelheim Pharmacy Satisfaction Pulse Survery, 2018. Data show consumer survey responses to the question: "If Amazon were to provide prescription drug filling services, how interested would you be in filling your prescription with them?"

clinics, PBM, and innovative digital capabilities. The firm will need to draw on its dynamic capabilities (Appendix 3 for an overview on the concept of dynamic capabilities) to meet current challenges existing in the marketplace and the future challenge of Amazon and PillPack.

Whether Amazon's entrance into the pharmacy market will fundamentally affect CVS Health's overall business, its ultimate competitive impact remains unknown. As the director of digital marketing, it is your role to understand these implications, provide guidance for the executive vice president of enterprise strategy and digital on what approach is best for the leadership team, business and shareholders and advance forward through the organization an appropriate strategy (Appendix 4 for information on the intuiting, interpreting, integrating and institutionalizing framework and the "feedforward"/"feedback" process of organizational learning and strategic renewal).

Should CVS Health:

- Ignore the threat.

- Combat Amazon's PillPack in the mail-order space (and how).

- Modify its current digital business model and offerings.

- Ignore any changes in digital, but determine ways to communicate its offerings.

- Focus on other sectors of its business, such as leveraging digital capabilities.

The director has a week to research and build a case to recommend a strategy to the executive vice president. In building a case, one needs to consider the strategic concepts of business models, strategic renewal and dynamic capabilities. With the executive vice president's feedback, the director will be presenting recommendations to CEO - Karen S. Lynch, the chief executive and the CVS board. What will it entail? What evidence will it require? What story will one need to share to make the case compelling? 


\section{References}

Aetna Mobile (2018), “Aetna mobile”, available at: https://benefits.hshs.org/getattachment/ 9858cbca-3c63-46fa-a23b0280567df94b/Aetna_Mobile_Flyer.pdf.aspx (accessed 22 August 2019).

Anderson, D. (2019), "CVS's business model, generic strategy and intensive growth strategies", available at: www.rancord.org/cvs-business-model-generic-competitive-intensive-growth-strategies (accessed 6 August 2020).

Bland and Osterwalder (2020), Testing Business Ideas, Wiley, Hoboken.

Comstock, J. (2015), "PillPack launches medication reminder app for iPhone, apple watch", available at: www.mobihealthnews.com/45152/PillPack-launches-medication-reminder-app-for-iphone-applewatch (accessed 23 August 2019).

Crossan, M., Lane, H.W. and White, R.E. (1999), "An organizational learning framework: from intuition to institution author (s)", The Academy of Management Review, Vol. 24 No. 3, pp. 522-537, available at: www.jstor.org/stable/259140

Customers Are Seeing Double at CVS/pharmacy This Fall, With More Rewards for ExtraCare Members (2012), "Customers are seeing double at CVS/pharmacy this fall, with more rewards for ExtraCare members", available at: https:/cvshealth.com/newsroom/press-releases/customersare-seeing-double-cvspharmacy-fall-more-rewards-extracare-members (accessed 23 August 2019).

CVS Caremark announces a corporate name change to CVS Health to reflect broader health care commitment (2014), "CVS caremark announces a corporate name change to CVS Health to reflect broader health care commitment", available at: https:/cvshealth.com/newsroom/press-releases/ cvs-caremark-announces-corporate-name-change-cvs-health-reflect-broader (accessed 23 August 2019).

CVS Caremark has become a frequent subject of government probes (2012), "CVS Caremark has become a frequent subject of government probes", available at: www.latimes.com/business/laxpm-2012-oct-24-la-fi-cvs-caremark-20121024-story.html (accessed 23 August 2019).

CVS Health at a Glance (2019), "CVS Health at a glance", available at: https://cvshealth.com/about/ facts-and-company-information (accessed 23 August 2019).

CVS Health to Acquire Aetna; Combination to provide consumers with a better experience, reduced costs, and improved access to health care experts in homes and communities across the country (2017), "CVS Health to acquire Aetna; combination to provide consumers with a better experience, reduced costs, and improved access to health care experts in homes and communities across the country", available at: https:/cvshealth.com/newsroom/press-releases/ cvs-health-acquire-aetna-combination-provide-consumers-better-experience (accessed 23 August 2019).

CVS Pharmacy Launches Breakthrough, end-to-end mobile payment experience (2016), "CVS pharmacy launches breakthrough, end-to-end mobile payment experience", available at: https:// cvshealth.com/newsroom/press-releases/cvs-pharmacy-launches-breakthrough-end-end-mobilepayment-experience (accessed 23 August 2019).

Daily, L. (2019), "Should you switch to a mail-order pharmacy? Here are the factors to consider", available at: www.washingtonpost.com/lifestyle/home/should-you-switch-to-a-mail-order-pharmacy-hereare-the-factors-to-consider/2019/01/07/8b56f87a-0ede-11e9-8938-5898adc28fa2_story.html (accessed 1 June 2020).

Drug prescription volume US (2019), "Drug prescription volume U.S", available at: www.statista.com/ statistics/238702/us-total-medical-prescriptions-issued/ (accessed 15 October 2019).

Farr, C. (2019), "The inside story of why amazon bought PillPack in its effort to crack the $\$ 500$ billion prescription market”, available at: www.cnbc.com/2019/05/10/why-amazon-bought-PillPack-for753-million-and-what-happens-next.html (accessed 23 August 2019). 
IJPHM 15,3

Fein, A. (2019), The 2019 Economic Report on US Pharmacies and Pharmacy Benefits Managers, Drug Channels Institute.

Fitzgerald, M. (2017), "Not just a pharmacy: CVS unveils its digital innovation", available at: www. fastcompany.com/3047646/not-just-a-pharmacy-cvs-unveils-its-digital-innovation-lab. (accessed 15 October 2019).

Garrity, M. (2019), “CVS to spend $\$ 325$ million on digital health care in 2019", available at: www. pharmacist.com/article/cvs-spend-325-million-digital-health-care-2019 (accessed 9 September 2019).

Ghezzi, A. (2018), "Digital startups and the adoption and implementation of lean startup approaches: effectuation, bricolage and opportunity creation in practice", Technological Forecasting and Social Change, Vol. 146, pp. 945-960, doi: 10.1016/j.techfore.2018.09.017.

Godman, H. (2016), "Retail health clinics: the pros and cons", available at: www.health.harvard.edu/ blog/retail-health-clinics-the-pros-and-cons-201601158979 (accessed 9 September 2019).

Gratto, J. and McConnell, C. (2016), "The dynamic environment of healthcare, management principles for healthcare professionals", available at: http://samples.jbpub.com/9781284081329/Chapter1. pdf (accessed 9 September 2019).

Hedgecock, S. (2015), "Pharmacy startup PillPack could change the way America takes its medicine", available at: www.forbes.com/sites/sarahhedgecock/2015/04/15/this-pharmacy-startup-wantsto-change-the-way-you-take-your-medicine/\#1309d9e67de0 (accessed 23 August 2019).

Leadem, R. (2018), "Seventeen incredible amazon PRIME facts and stats", available at: www. entrepreneur.com/slideshow/304271 (accessed 23 August 2019)

Mail-Order Pharmacy Startups and Opening a Mail Order Pharmacy Business (2020), available at: https://pharmacy-staffing.com/pharmacy-start-ups/mail-order-pharmacy-startups/\#: : text=Specializationhasledtoincreased,significantcustomersatisfaction,andloyalty (accessed 1 June 2020).

Minto, B. (2002), The Pyramid Principle: Logic in Writing and Thinking, Financial Times Prentice Hall, London.

MinuteClinic History (2019), "MinuteClinic history", available at: www.cvs.com/minuteclinic/visit/ about-us/history (accessed 23 August 2019).

MinuteClinic Services (2018), "MinuteClinic services”, available at: www.cvs.com/minuteclinic/services (accessed 23 August 2019).

MinuteClinic Video Visit (2018), "MinuteClinic video visit", available at: www.cvs.com/minuteclinic/ virtual-care/video-visit (accessed 23 August 2019).

Nusca, A. and Rapp, N. (2017), "This is where whole foods (soon, amazon) has stores in the US", available at: https://fortune.com/2017/06/16/amazon-whole-foods-stores-locations/ (accessed 23 August 2019).

Pharmacy: Manage, transfer, and refill prescriptions online: CVS Pharmacy (2019), "Pharmacy: Manage, transfer, and refill prescriptions online: CVS pharmacy”, available at: www.cvs.com/ pharmacy/v2/\#/pharmacy?icid=cvsheader:pharmacy (accessed 23 August 2019).

Specialty Pharmacy (2017), available at: www.pharmacist.com/specialty-pharmacy (accessed 1 June 2020).

Tabuchi, H. (2015), "How CVS became nation's biggest healthcare company”, available at: www. seattletimes.com/business/how-cvs-became-nations-biggest-health-care-company/ (accessed 23 August 2019).

Teece, D.J. (2018), "Business models and dynamic capabilities", Long Range Planning, Vol. 51 No. 1, pp. 40-49, doi: 10.1016/j.lrp.2017.06.007.

Teece, D.J. (2010), "Business models, business strategy, and innovation”, Long Range Planning, Vol. 43 Nos 2/3, pp. 172-194, doi: 10.1016/j.lrp.2009.07.003.

Yanofsky, D. and Zhou, Y. (2017), "Eight out of 10 Americans are within 10 miles of a CVS", available at: https://qz.com/1146577/cvs-and-aetna-aet-82-of-americans-are-within-10-milesof-the-pharmacy/ (accessed 23 August 2019). 


\section{Further reading}

$\$ 4$ prescriptions (2019), “\$4 prescriptions", available at: www.walmart.com/cp/ $\$ 4$-prescriptions/ 1078664 (accessed 22 August 2019).

Aetna Announces Attain, a Personalized Well-being Experience Combining Health History with the Apple Watch (2019), "Aetna announces attain, a personalized well-being experience combining health history with the apple watch", available at: https:/cvshealth.com/newsroom/pressreleases/aetna-announces-attain-a-personalized-well-being-experience-that-combines-health-historywith-apple-watch-information-to-empower-better-health (accessed 22 August 2019).

Cigna and Express Scripts Further Enhance Customer Service Offerings Through New Collaboration with Amazon Alexa (2019), "Cigna and express scripts further enhance customer service offerings through new collaboration with amazon alexa", available at: www.cigna.com/ newsroom/news-releases/2019/cigna-and-express-scripts-further-enhance-customer-service-offeringsthrough-new-collaboration-with-amazon-alexa (accessed 22 August 2019).

Cigna to Acquire Express Scripts for $\$ 67$ Billion (2018), “Cigna to acquire express scripts for $\$ 67$ billion”, available at: www.cigna.com/newsroom/news-releases/2018/cigna-to-acquire-expressscripts-for-67-billion (accessed 22 August 2019).

Court, E. (2018), "Amazon acquisition of online pharmacy startup PillPack sends healthcare stocks into a nose dive", available at: www.marketwatch.com/story/amazon-acquisition-of-online-pharmacystartup-PillPack-sends-health-care-stocks-into-a-nosedive-2018-06-28 (accessed 23 August 2019).

CVS Health - Corporate Social Responsibility Report [PowerPoint slides] (2017), "CVS Health Corporate social responsibility report [PowerPoint slides]”, available at: https:/cvshealth.com/ sites/default/files/2017-csr-full-report.pdf (accessed 9 September 2019).

CVS Health About (2019), "CVS Health About”, available at: https://cvshealth.com/about (accessed 23 August 2019).

CVS Health (2019), “CVS Health”, available at: https:/fortune.com/global500/2019/cvs-health (accessed 23 August 2019).

CVS Pharmacy Store Pickup (2019), “CVS Pharmacy store pickup”, available at: www.cvs.com/content/ storepickup (accessed 23 August 2019).

Express Scripts to launch stand-alone digital health formulary in 2020 (2019), "Express scripts to launch stand-alone digital health formulary in 2020", available at: www.mobihealthnews.com/news/northamerica/express-scripts-launch-stand-alone-digital-health-formulary-2020 (accessed 23 August 2019).

Howland, D. (2016), "Walgreens, rite aid delay merger amid antitrust concerns", available at: www. retaildive.com/news/walgreens-rite-aid-delay-merger-amid-antitrust-concerns/428695/ (accessed 23 August 2019).

Howland, D. (2017), "Walgreens wins FTC approval to buy $2 \mathrm{~K}$ rite aid stores for $\$ 4.3 \mathrm{~B}$, available at: www.retaildive.com/news/walgreens-wins-ftc-approval-to-buy-2k-rite-aid-stores-for-43b/ 505199/ (accessed 23 August 2019).

Klinger, E. (2017), "2017 generic drug access and savings in the US report, association for accessible medicines", available at: https:/accessiblemeds.org/resources/blog/2017-generic-drug-accessand-savings-us-report (accessed 6 September 2018).

Mari, A. (2018), "CVS boosts innovation investment to reinvent pharmacies in Brazil", available at: www.forbes.com/sites/angelicamarideoliveira/2018/09/27/cvs-boosts-innovation-investmentto-reinvent-pharmacies-in-brazil/\#137870957c6e (accessed 23 August 2019).

Merlo, L. (2019), “Creating value by transforming the consumer health experience [PowerPoint slides]", available at: https://s2.q4cdn.com/447711729/files/doc_events/2019/InvestorDay2019/2019-CVSInvestor-Day-Full-Presentation.pdf (accessed 23 August 2019).

Mikulic, M. (2019), "U.S. Mail pharmacies by Rx drugs market share US 2014 Vs. 2018”, available at: fromwww.statista.com/statistics/749237/mail-pharmacies-ranked-by-rx-market-share-in-us/ (accessed 23 August 2019). 
IJPHM

15,3

348

Polack, E. (2019), "Cigna and express scripts further enhance customer service offerings through a new collaboration with amazon Alexa", available at: www.cigna.com/newsroom/news-releases/2019/ cigna-and-express-scripts-further-enhance-customer-service-offerings-through-new-collaborationwith-amazon-alexa (accessed 23 August 2019).

Prairie, E. (2019), "Optum completes acquisition of DaVita medical group from DaVita”, available at: www. unitedhealthgroup.com/newsroom/2019/2019-06-19-optum-davita-medical-acquisition.html (accessed 23 August 2019).

Retail Pharmacy USA (2018), "Retail pharmacy USA", available at: www.walgreensbootsalliance.com/ about/company/retail-pharmacy-usa/ (accessed 23 August 2019).

Shahbandeh, M. (2018), “CVS Health's revenue 2010-2017 by segment”, available at: www.statista.com/ statistics/261282/cvs-caremarks-revenue-by-segment/ (accessed 23 August 2019).

Truong, K. (2018), "Walgreens links up with FedEx for nationwide next-day delivery service”, available at: https://medcitynews.com/2018/12/walgreens-links-up-with-fedex-for-nationwide-next-daydelivery-service/ (accessed 23 August 2019).

Turea, M. (2020), “6 Ways amazon plans to disrupt the pharmacy business”, available at: https:// healthcareweekly.com/amazon-pharmacy/ (accessed 6 August 2020).

Vendor Benefit Management Simplified (2021), "Vendor benefit management simplified", available at: https:/payorsolutions.cvshealth.com/insights/vendor-benefit-management-simplified

Walgreens Boots Alliance Reports Fiscal Year 2018 Results (2019), "Walgreens boots alliance reports fiscal year 2018 results", available at: www.walgreensbootsalliance.com/newsroom/news/ walgreens-boots-alliance-reports-fiscal-year-2018-results.htm (accessed 23 August 2019).

Walgreens Pharmacy - NYP On Demand (2019), "Walgreens Pharmacy - NYP on demand", available at: www.walgreens.com/topic/pharmacy/healthcare-clinic/new-york-presbyterian-on-demand. jsp (accessed 8 September 2019). 


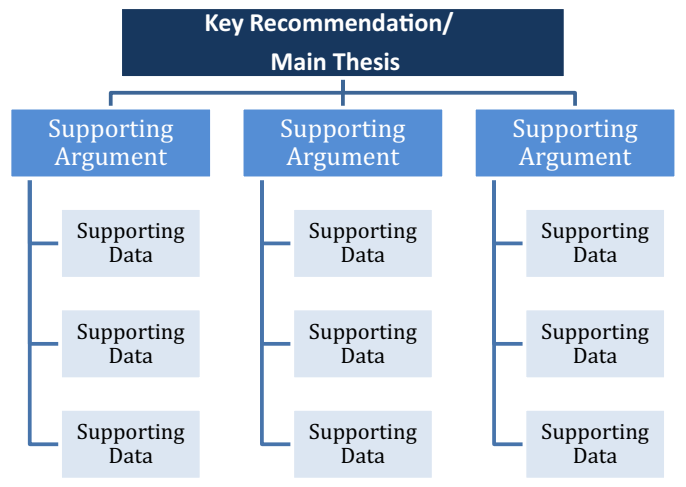

Source: Adapted from Minto (2002)
349

Figure A1 .

The pyramid principle outlines a cogent framework for presenting recommendations with supportive arguments and data to advocate a business case

The pyramid principle is a framework used to help structure reports and presentating make a decisive impact on your stakeholders. The hierarchical structure helps create a logical and datadriven storyline to communicate ideas clearly and succinctly (Minto, 2002).

The pyramid principle suggests starting the presentation with an introductory key message first, followed by three key supporting arguments. One can then break these arguments down further into three areas to offer supporting data subsequently, thereby strengthen the overall recommendations made.

The key message is to establish a set up for the presentation using four guiding segments that build the basis for sharing a compelling narrative or "story":

- Situation: Briefly describe the current situation of the market and company.

- Complication: What is the problem at hand for the company.

- Question: Define the overarching question to address.

- Recommendation: Put forth the core recommendation (along with the three high-level arguments to support the recommendation).

After the presenter provides the supporting arguments and back up data, he/she can connect the pieces in the wrap-up section. Elements within this section can include potential steps forward, risk and mitigation plan and finally, the conclusion or take-home point.

\section{Appendix 2. Business models}

A business model describes the design of the value creation, delivery and capture mechanisms that firms use (Teece, 2010). A business model defines how the enterprise delivers value to customers, entices customers to pay for value and converts those payments to profit. A strong business model is essential to the commercialization of technology. It can clearly define the resources needed to deliver the value proposition. Components of a business model include: 
IJPHM

15,3

\section{Desirability risk}

Customers aren'tinterested

The risk is that the market a business is targeting is too

small; that too few customers

want the value proposition; or

that the company can't reach,

acquire, and retain targeted

customers.

\section{0}

Figure A2.

Major Sectors of the Business Model Canvas

\section{Feasibility risk}

We can't build and deliver

The risk is that a business can't get access to key resources (technology, IP, brand, etc.), can't develop capabilities to perform key activities, or can't find key partners to build and scale the value proposition.

\section{Key Resources Key Activities Partners}

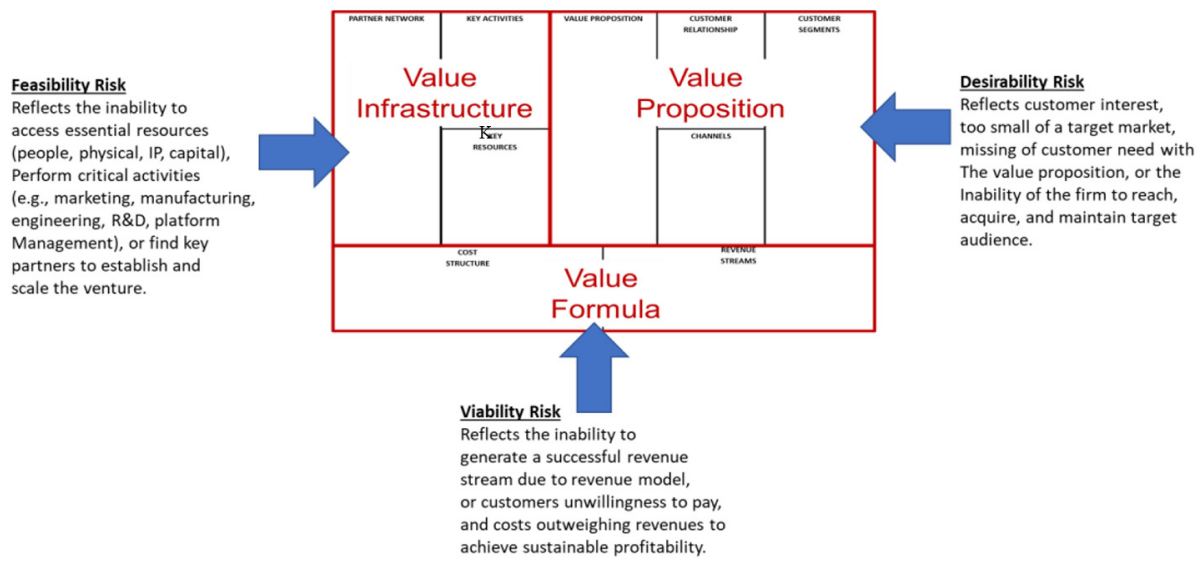

Source: Adapted from Bland and Osterwalder, 2020 The value proposition, or the nability of the firm to reach, acquire, and maintain target audience.
Source: Adapted firom Bland and Osterwalder, 2020

\section{Viability risk}

We can't earn enough money The risk is that a business can't generate successful revenue streams, that customers are unwilling to pay (enough), or that the costs are too high to make a sustainable profit. 


\section{Appendix 3. Dynamic capabilities}

Dynamic capabilities include the sensing, seizing and transforming needed to design, implement, and refine a business model (Teece, 2018). A strong business model provides an organization with adequate profits to sustain and improve its capabilities and resources. Dynamic capabilities and strategy combine to create and refine a defensible business model, which guides organizational transformation. The framework below demonstrates the influence of dynamic capabilities and strategy on business model development. Firms can use this approach for effective decision-making as the firm senses, seizes and transforms opportunities:

\section{CVS Health}

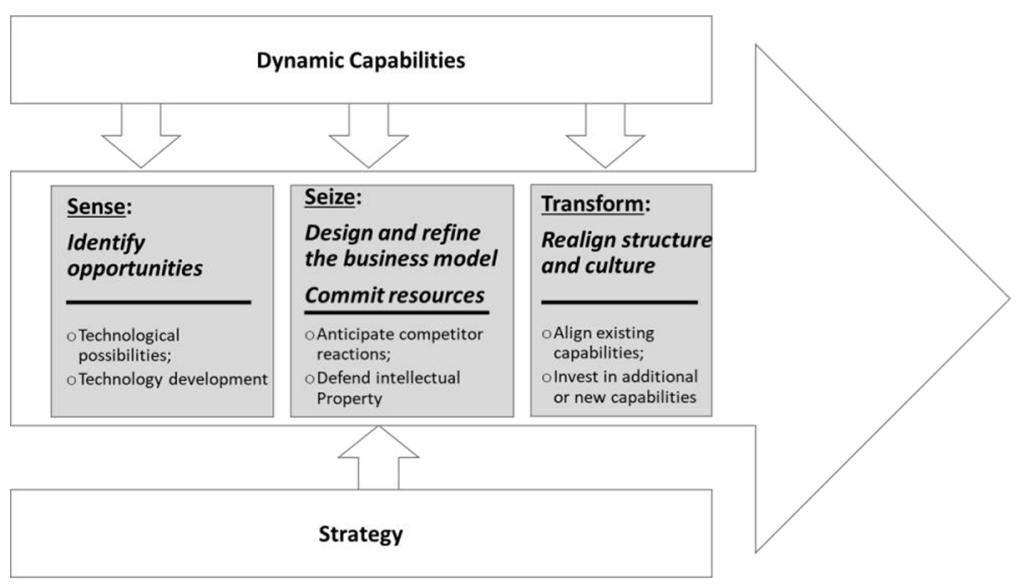

Figure A3.

Teece's Sense, Seize, Transform Depiction of How Firms Integrate Their Dynamic Capabilities and Strategy to

Design, Implement, and Refine a Business Model. Adapted from Teece (2018)

Key questions:

- What technological possibilities or developments can CVS use now that PillPack is in the market? Is it worth it?

- If CVS adapts, what will PillPack do to react to this new digital strategy?

- Can CVS align its existing capabilities and/or obtain new capabilities?

\section{Appendix 4. The intuiting, interpreting, integrating and institutionalizing framework for organizational learning and strategy renewal}

The 4Is framework is an organizational learning concept that firms use to achieve strategic renewal. It involves the advancement of new knowledge, innovations and ideas as part of an exploratory process such that the firm ultimately "buys in" an embodies such as new routines, policies and practices to exploit (Crossan, 1999). The 4Is framework involves four essential processes, namely, intuiting, interpreting, integrating and institutionalizing (4I's). The 4I's link the individual, group and organizational levels, which define the structure through which learning takes place.

Four key premises underly the strategic renewal framework: 
IJPHM

15,3

\section{2}

Figure A4.

How the 4Is flow across the organization, engaging the "feedforward" and "feedback" processes that enable new knowledge, ideas, innovations to advance through an organization and embed as set routines and practices to exploit
(1) Premise 1: Organizational learning involves a tension between assimilating new learning (exploration) and using what the firm has gained as new knowledge (exploitation).

(2) Premise 2: Organizational learning is multilevel: individual, group and organization.

(3) Premise 3: Social and psychological processes link the three levels of organizational learning: intuiting, interpreting, integrating and institutionalizing.

(4) Premise 4: Cognition affects the action.

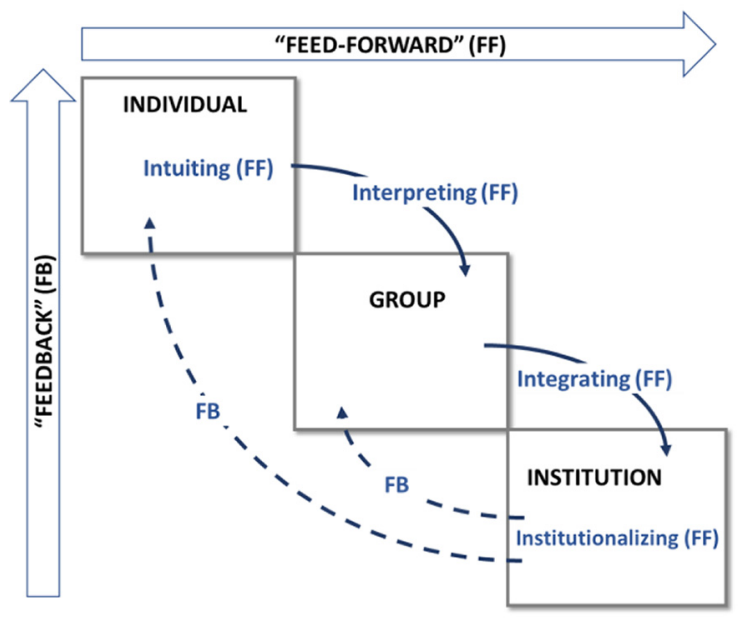

Source: Adapted from Crossan et al. (1999)

\begin{tabular}{|c|c|c|c|c|}
\hline $\begin{array}{l}\text { Level } \\
\text { Process }\end{array}$ & $\begin{array}{l}\text { Individual } \\
\text { Intuiting }\end{array}$ & $\begin{array}{l}\text { Group } \\
\text { Interpreting }\end{array}$ & Integrating & $\begin{array}{l}\text { Organization } \\
\text { Institutionalizing }\end{array}$ \\
\hline Inputs & Experiences & Language & Shared understandings & Routines \\
\hline & Images & Cognitive maps & Mutual adjustment & Diagnostic systems \\
\hline Outcomes & Metaphors & $\begin{array}{l}\text { Conversation } \\
\text { Dialogue }\end{array}$ & Interactive systems & Rules and procedures \\
\hline
\end{tabular}

Table A1.

Source: Adapted from Crossan et al. (1999)

Key questions:

- Should CVS invest in a corporate renewal strategy to respond to PillPack?

- Should CVS strategically position itself as a one-stop-shop or a community prescription provider?

- How will CVS's assets facilitate its transformation? 


\begin{abstract}
About the authors
John M. York, PharmD, MBA, CEO of Akita Biomedical, serves as faculty at the University of California, San Diego (UCSD, Rady School of Management and Institute for the Global Entrepreneur) and as an adjunct professor at the Ernest Mario School of Pharmacy. He currently teaches entrepreneurship, marketing and special projects. York also serves as a National Science Foundation Innovation CORPS ${ }^{\mathrm{TM}}$ instructor at UCSD. York also teaches on entrepreneurship and pharmaceutical industry topics globally including programs in Cambridge, UK; Ahmedabad, India; and Tsukuba, Japan. He coaches startups in the US, Europe, Japan, and Korea. As the first pharmaceutical industry post doc at the Ernest Mario School of Pharmacy, York brings over 30 years in the life science business with experience at Bristol Meyers Squibb, Amgen, Allergan, and Health Dimensions in medical, sales, marketing and management. He has a PharmD from the University of Michigan, an MBA at Kelley School of Business (Indiana University), and multiple certificates in life sciences business management and marketing at the University of California, Berkeley. He has over 31 published papers covering a diversity of business, pharmacoeconomic, basic science, and clinical topics. His editorial responsibilities include associate editor, Cancer Control and reviewer, Archives of Business Administration and Management. He currently is pursuing at a doctorate in business administration at the Cranfield School of Management (Cranfield, UK). John M. York is the corresponding author and can be contacted at: johnyork@akitabiomedical.com

Kaley Lugo received her PharmD and MBA at the University of Rhode Island. She went on to complete her post-doctoral fellowship in partnership with the Rutgers Pharmaceutical Industry Program, where she held the position of chief fellow. Dr Lugo now works in Medical Affairs at Daiichi Sankyo with a focus in oncology.

Lukasz Jarosz received his bachelor's degree in Chemistry from Montclair State University and his PharmD at the Ernest Mario School of Pharmacy. Dr Jarosz went on to complete his post-doctoral fellowship in partnership with the Rutgers Pharmaceutical Industry Program and now works for the Business Development group at Daiichi Sankyo specializing in oncology transactions.

Michael Toscani, PharmD is a Research Professor and past Director for the Rutgers Institute for Pharmaceutical Industry Fellowships at the Ernest Mario School of Pharmacy. He has held senior management positions in the pharmaceutical, contract research and health and disease management industries over the past 30 years. Dr Toscani is a frequent national speaker and author in both the scientific and health-care management areas. He currently serves on the editorial board of the Journal of Population Health Management (formerly Disease Management), Specialty Pharmacy Journal and was on the editorial boards of the Journal of Clinical Outcomes Management, Journal of Clinical Research and Pharmacoepidemiology and the Journal of Osteopathic Medicine. Dr Toscani is active in many charitable and non-profit organizations such as: Thomas Edison State University Foundation Board, the American Cancer Society and Rotary International. Dr Toscani received his bachelor of science in pharmacy and PharmD from St. John's University College of Pharmacy. He completed a two-year postdoctoral research and teaching fellowship in infectious diseases at Hartford Hospital.
\end{abstract}

For instructions on how to order reprints of this article, please visit our website:

www.emeraldgrouppublishing.com/licensing/reprints.htm

Or contact us for further details: permissions@emeraldinsight.com 